\title{
ORALIDADE E A ÉTICA NA MEDIAÇÃO DA LITERATURA
}

\section{ORALIDAD Y LITERATURA SOBRE MEDIACIÓN ÉTICA}

\author{
Sueli Bortolin - bortolin@uel.br \\ Doutora em Ciência da Informação pela Faculdade de Filosofia e Ciências \\ da UNESP Campus de Marília. Professora do Departamento de Ciência \\ da Informação da Universidade Estadual de Londrina (UEL). \\ Oswaldo Francisco de Almeida Júnior - ofaj@ofaj.com.br \\ Doutor em Ciências da Comunicação pela Universidade de São Paulo \\ (USP). Professor do Programa de Pós-Graduação em Ciência da \\ Informação da Universidade Estadual Paulista (UNESP/Marília).
}

\section{RESUMO}

Introdução: O presente trabalho aborda as duas oralidades, a Ancestral e a Nova Oralidade. A primeira é aquela produzida presencialmente, por meio da voz viva e que está presente diariamente na vida em sociedade. A segunda, também presente na vida diária, diferencia-se da primeira por ser mediatizada, isto é, construída e disseminada por uma tecnologia. Trata-se de um trabalho teórico que tem como respaldo autores da área de Ciência da Informação, Artes e Letras.

Objetivo: Provocar reflexões nos profissionais da informação quanto a importância da utilização dessas oralidades no cotidiano de diferentes espaços, seja ele, informacional, cultural, educacional, empresarial ou de pesquisa.

Metodologia: Escolheu-se o método bibliográfico para essa investigação.

Conclusões: Conclui-se que há um movimento, embora tímido, em múltiplos espaços propondo narrativas orais para diversificadas faixa etárias. Há também a inclusão e disseminação de vozes nas redes de computadores, possibilitando um aglutinamento social e cultural.

Palavras-chaves: Oralidade. Mediação da literatura. Ética profissional. 


\section{CONSIDERAÇÕES INICIAIS}

Esse trabalho é um fragmento da tese de doutorado "Mediação Oral de Literatura: a voz dos bibliotecários lendo ou narrando", que teve como metodologia de investigação o método bibliográfico.

Mesmo tendo o conhecimento de que a tendência atual é pela valorização da linguagem em suas diferentes formas, acredita-se que a palavra verbalizada continua sendo a unidade propulsante da comunicação entre os indivíduos. Propositadamente utilizou-se aqui propulsante no lugar de propulsora para destacar o pulsar das palavras na vida dos indivíduos e consequentemente em suas relações.

Os sons das palavras atraem. A palavra falada, tecida, tramada seduz. Tramada no sentido de estender e trançar fios no tear, portanto colocar as palavras no tear traz felicidade e prazer. ${ }^{1}$

Isso tudo desperta, em várias áreas e num grande número de pesquisadores ${ }_{2}$ o interesse em estudar a oralidade e também em acreditar no argumento dos medievalistas de que um texto escrito um dia já existiu oralmente, um exemplo, é a tecitura ${ }^{2}$ desse trabalho. Ao produzi-lo automaticamente, e quase sem perceber, um texto foi sendo oralizado em nossas cabeças e aos poucos e por meio dos dedos no teclado, foi tomando a sua forma escrita.

Toda fala escrita ou oral tem a sua especificidade. A escrita, por exemplo, congela um texto e a oralidade dispersa. Outra característica que as diferencia é que a oralidade não exige comprovação da autoria, a escrita sim. Para Zumthor (2005, p. 53): "a voz é nômade, enquanto que a escrita é fixa."

Estudar a voz é fascinante e esse interesse talvez se explique

[...] porque nossa mais remota lembrança de um ato de comunicação esteja ligada à voz, afinal comunicamos nosso nascimento com ela o primeiro choro. Por outro lado, é comum representar a morte pelo último grito ou pelas últimas palavras. Sob essa perspectiva, pode-se afirmar que a expressão oral - ou vocal - está presente no início e no

\footnotetext{
${ }^{1}$ Essa é uma referência as Cantigas de Tear que "são cantigas medievais galego-portuguesas derivadas do modelo provençal de chanson de toile [canção de tecido] em que se cantam afazeres relacionados com o tear, no tratamento do linho ou da lã [...]." (MONIZ, Antônio; PAZ, Olegário.

Dicionário breve de termos literários. Lisboa: Editorial Presença, 1997. p. 39).

${ }^{2}$ Tecitura - "[...] é mais apropriada a grafia com 'c' para significar 'urdidura/organização', na medida em que se escreve tecer, tecido, tecelagem, tecelaria, tecidual, tecedura, tecedeira. Já ao falar em música é natural que se grafe tessitura, pois nesse campo a língua portuguesa incorporou os exatos termos do italiano." (PIACENTINI, Maria Tereza de Queiroz. Não tropece na língua. Disponível em: <http://www.resenhas.com/resenhas/ver.asp?id=1679\&auth=39449\&>. Acesso em: 29 nov. 2009).
} 
fim da existência humana, e o que a voz simboliza nessas representações de vida e morte - o primeiro choro e as últimas palavras - é a interação do sujeito com o outro. Enquanto há palavras (voz), há vida: antes do primeiro choro (voz) não se nasce para o outro. (MEDEIROS, 2007, p. 71-72).

Pensar em voz, choro, vida e morte é possível, quase que automaticamente, lembrar de uma cena marcante do filme Tomates Verde Fritos. Para o leitor que não o assistiu, inclui-se aqui um relato sucinto do diálogo ocorrido entre dois personagens: Idgie uma das protagonistas do filme era irmã de Buddy, Buddy era um rapaz encantador, que quando precisava acalmá-la, em sua rebeldia, contava histórias. Eles eram muito unidos. Certo dia ele vai passear com uma garota chamada Ruth Jamison e Idgie, como sempre vai atrás. Quando estavam próximo a um lago, ele diz para Ruth:

- Acha que é um lago grande? Devia ter visto o que havia aí ao lado da nossa casa, Nadávamos e pescávamos, sinto falta. Sinto mesmo!

Ruth pergunta:

- O que aconteceu com ele? Secou?

Buddy responde:

- Não, pior que isso. No último outono um bando de patos, cerca de 40 ou 50 pousaram bem no meio dele. E enquanto estavam lá, aconteceu esse caso: a temperatura caiu tanto que o lago congelou e em 3 segundos... assim...

Ruth lamentou:

- Pobres patinhos. Morreram?

Buddy com um olhar matreiro, respondeu:

- Não, levantaram voo levando o lago junto. Agora esse lago está em algum lugar da Geórgia. ${ }^{3}$

Em seguida Buddy corre atrás do chapéu de Ruth e morre ao ser atropelado por um trem. A história de Buddy passa a ser recontada por Idgie. Anos mais tarde Ruth Jamison no leito de morte diz a Idgie que quer ouvir a história do lago, Idgie narra e assim Ruth consegue se desvencilhar do corpo corroído pelo câncer.

Ao assistir esse texto fílmico é possível lembrar-se do escritor Alfred Döblin quando argumenta: "A maioria de nossas funções humanas é singular: não precisamos de ninguém para respirar, andar, comer ou dormir. Mas precisamos dos outros para falar, para que nos devolvam o que dissemos. A linguagem, declarou Döblin, é um modo de amar os outros." (MANGUEL, 2008, p. 17).

\footnotetext{
${ }^{3}$ TOMATES verdes fritos. Direção: Jon Avnet. [S.I.]: Distribuidora: Universal Pictures, 1991. 1 DVD (136 min.), color. Título original: Fried Green Tomatoes.
} 
Nesse sentido, esse trabalho aborda as temáticas: oralidade ancestral, nova oralidade, mediação da literatura e o comportamento ético do mediador.

\section{Oralidade Ancestral}

Ao estudar a oralidade ancestral optou-se, entre outros autores, em apropriarse de Paul Zumthor e isso é suficientemente positivo para que o sentido preconceituoso da palavra ancestral (antigo) leve o leitor a pensar quanto a ancestralidade cultural e a memória dos nossos antepassados podem contribuir com a temática oralidade.

Para Jeanne Marie Gagnebin prefaciadora da obra de Walter Benjamin intitulada Magia e técnica, arte e política: ensaios sobre literatura e história da cultura,

o ritmo do trabalho artesanal se inscreve em um tempo mais global, tempo onde ainda se tinha, justamente, tempo para contar. [...] de acordo com Benjamin os movimentos precisos do artesão, que respeita a matéria que transforma, têm uma relação profunda com a atividade narradora, já que esta também é, de certo modo, uma maneira de dar forma à imensa matéria narrável, participando assim da ligação secular entre a mão e a voz, entre o gesto e a palavra. (GAGNEBIN, 1994, p. 11).

Pensando dessa forma Nanci Gonçalves da Nóbrega, bibliotecária e contadora de histórias, defende: "[...] todos os narradores se alimentaram da experiência transmitida de pessoa a pessoa e não é segredo que dentre as narrativas escritas as melhores são as mais parecidas com as histórias orais transmitidas pelo grande número de narradores anônimos." (2009, p. 102). Não apenas narradores anônimos, mas também autores anônimos. A dúvida a quem deve ser atribuída a autoria é uma das características do texto oral e assim diz a sabedoria popular: quem conta um conto aumenta um ponto.

A Teoria da Literatura, "um dos quatro ramos da Ciência da Literatura, cujo objectivo é a reflexão teórica sobre o texto literário [...]". (MONIZ; PAZ, 1997, p. 211) avalia que num texto impresso, há uma coautoria. Dessa forma pode-se afirmar que na leitura coletiva também ocorre esse fenômeno e nela os autores, são, além do escritor, o leitor-narrador e o leitor-ouvinte, pois a narrativa oral ao ser executada perde a autoria original. Destaca-se aqui que os conceitos de Bortolin (2010, p. 22) 
de "leitor-narrador - é todo indivíduo que medeia o encontro do leitor com diferentes textos (de origem escrita ou oral), utilizando o seu suporte vocal para ler ou narrar" e de "leitor-ouvinte é todo indivíduo que tem a sua leitura mediada, isto é, que recebe a interferência oral de um mediador para se encontrar com diferentes textos, podendo também ser chamado de leitor que lê com os ouvidos." (BORTOLIN, 2010, p. 22).

Vale enfatizar-se também que o texto oralizado está antes de tudo nas lembranças do indivíduo que o ouve, sendo dependente da memória dele, mas também dos recortes textuais que o narrador fará no estado de performance literária. Performance que na acepção de Bortolin (2010, p. 51) "é o envolvimento intenso e integral do narrador com o leitor-ouvinte no momento da leitura."

Paul Zumthor objetivando fazer um exame crítico de conceitos consensuais existentes na década de 70 a respeito de oralidade viaja por diferentes países do mundo (incluindo o Brasil), observando os praticantes da voz, entre eles: repentistas, cordelistas, cançonetistas, panegiristas, poetas da voz, recitantes...

Esses praticantes já o impressionavam desde a infância. Em seu livro Performance, percepção, leitura, por exemplo, ele conta que:

Havia um texto, em geral fácil, que se podia comprar por alguns trocados, impresso grosseiramente em folhas volantes. Além disso, havia o jogo. O que nos havia atraído era o espetáculo. Um espetáculo que me prendia, apesar da hora de meu trem que avançava e me fazia correr em seguida até a Estação do Norte. (ZUMTHOR, 2007, p. 28).

Lendo essa e as demais obras desse autor, publicadas em língua portuguesa, foi possível perceber que sua pesquisa-viagem permitiu a Zumthor mapear, muitas vezes, num mesmo território, características semelhantes e destoantes entre os praticantes da voz, porém o que para ele existe em comum é que

A enunciação da palavra ganha em si mesma valor de ato simbólico: graças à voz, ela é exibição e dom, agressão, conquista e esperança de consumação do outro; interioridade manifesta, livre da necessidade de invadir fisicamente o objeto de seu desejo; o som vocalizado vai de interior a interior e liga [...] duas existências. (ZUMTHOR, 2010, p. 13).

Observar o fascínio que o som vocalizado exerce nas crianças, por exemplo, é tarefa fácil, pois, mesmo sem qualquer estudo de psicologia ou pedagogia, uma 
mãe analfabeta cantarola músicas de ninar ao seu bebê como forma de acalmá-lo, e ele adormece.

O mesmo halo performático, isto é, a ambiência propícia para a recepção do texto pelo leitor-ouvinte, acontecia nas narrativas ancestrais ao redor do fogo, em frente às lareiras, nas mesas das tabernas etc. Isso porque "[...] as histórias que as pessoas contam entre si criam tecido forte que pode aquecer as noites espirituais e emocionais mais frias." (ESTÉS, 1998, p. 38).

Pode-se inferir que essa autora ao falar em "tecido forte" em seu texto, deve estar se referindo apenas ao relacionamento em família e não aos grupos públicos com pessoas sem vínculos anteriores. Destaca-se, no entanto, que há uma diferença considerável entre a narrativa coletiva e o recolhimento carinhoso nos braços dos membros da família, pois, nesta ambiência, a tendência é que esse ato seja carregado de carinho. E é ali, dependendo do texto, que a criança tem medo ou adormece e sonha. Isso, porém, não quer dizer que no momento das narrativas coletivas não exista afetividade. Há sim, em especial, no uso da voz, quando o narrador lê, conta, canta melodiosamente uma canção. Quando olha com respeito e igualdade nos olhos de uma pessoa.

Outra contribuição para essa temática está no livro A Cidade das palavras: as histórias que contamos para saber quem somos de Alberto Manguel quando ele comenta:

[...] as histórias podem vir em nosso socorro. Elas podem curar, iluminar, indicar o caminho. Sobretudo, podem nos recordar nossa condição, romper a aparência superficial das coisas, dar a ver as correntezas e abismos subjacentes. As histórias podem alimentar nossa mente, levando-nos talvez não ao conhecimento de quem somos, mas ao menos à consciência de que existimos - uma consciência essencial, que se desenvolve pelo confronto com a voz alheia. (2008, p. 19).

Dessa forma, afirma-se que os praticantes da voz (seja ele contemporâneo ou tradicional) e as narrativas escutadas são inesquecíveis, pois é

[...] ouvindo histórias que se pode sentir (também) emoções importantes, como a tristeza, a raiva, a irritação, o bem-estar, o medo, a alegria, o pavor, a insegurança, a tranquilidade, e tantas outras mais, e viver profundamente tudo o que as narrativas provocam em quem as ouve - com toda a amplitude, significância e verdade que 
cada uma delas fez (ou não) brotar... Pois é ouvir, sentir e enxergar com os olhos do imaginário! (ABRAMOVICH, 2001, p. 17)

Na atualidade é perceptível que a narrativa oral de histórias, ao contrário do que muitas pessoas pensam, não é tarefa apenas das mães, avós, babás e professoras.

Narrar histórias não é só para mulheres. Até no séc. XVIII segundo Gomes (2005, p. 29) "[...] o ato de contar histórias estava associado quase exclusivamente aos homens, e muito raramente às mulheres". Hoje, talvez por terem a Educação Infantil e o Ensino Fundamental maior presença de mulheres, elas acabam exercendo essa função. Mesmo assim, ainda há muitos homens que contam histórias causando encantamento. Em terras brasileiras podemos citar entre outros: Chico dos Bonecos, Roberto Carlos Ramos, Ilan Brenman, Celso Sisto e Francisco Gregório Filho.

O envolvimento de homens e mulheres com "a arte do contador de histórias tornou-se um gênero muito popular [...] com recursos mínimos, voz e mãos nuas, o contador de histórias rompe a quarta parede ${ }^{4}$, dirige-se diretamente ao público [...]." (PAVIS, 1999, p. 69) e "cada narrador [...] imprime na história suas marcas: vivências pessoais, lembranças próprias." (FERNANDES, 2002. p. 25).

Comparando o perfil dos narradores de histórias tradicionais com os da contemporaneidade, os de antigamente, em sua maioria eram pessoas mais velhas, que por maior vivência temporal e memória acumulada, gostavam de compartilhar conhecimentos reais ou imaginados, como os da atualidade.

Analisando esse grupo de mediadores Montenegro (2001, p. 152) comenta:

\begin{abstract}
A capacidade de narrar uma história, um fato, uma experiência ou mesmo um sentimento está associada a dois fatores: por um lado, à descrição dos detalhes dos elementos que são projetados, de forma tão viva e rica que se assemelham a um quadro que vai sendo redesenhado às nossas vistas: por outro lado, à capacidade de recuperar o lado imaginário do que era vivenciado individual e coletivamente em relação ao acontecimento narrado. $\mathrm{Na}$ associação dessas duas ordens de fatores (a descritiva e a imaginária) descobrem-se as condições básicas de um narrador.
\end{abstract}

\footnotetext{
4“Quando o dramaturgo alemão [Brecht] propõe romper a 'quarta parede' quer também derrubar a porta do teatro e eliminar o isolamento entre o 'mundo mágico da cena' e a 'vida real'. (AYER, Maurício. Um ator não é apenas um repetidor de falas. Disponível em: <http://www.wooz.org.br/teatroator.htm>. Acesso em: 10 jan. 2009).
} 
Esse panorama de pessoas mais idosas cumprindo a função de narrador tem mudado por fatores: econômicos (adiamento da aposentadoria, acúmulo de funções para complementar a renda familiar), socioculturais (desvalorização do pensamento dos mais velhos), ideológicos (aproveitamento do tempo com outros afazeres), tecnológicos (forte apelo das mídias) e mercantilistas (indústria cultural).

Abordando em sua dissertação de mestrado a profissionalização dos contadores de histórias, Fleck (2009, p. 24) destaca:

A Classificação Brasileira de Ocupações, documento que reconhece, nomeia e codifica os títulos e descreve as características das ocupações do mercado de trabalho brasileiro, não registra o contador de histórias como uma profissão. Entretanto, sob o código 2625-05, apresenta-o como um sinônimo para a ocupação de "ator".

A autora demonstra que na atualidade está havendo uma tendência de profissionalização dessa função, porém, independentemente se o leitor-narrador for um membro da família ou um profissional, Sousa (2008) acerta ao afirmar que só

quem já teve o privilégio de ouvir histórias da boca de um contador expressivo tem noção do prazer que é compartilhar de uma reunião onde a inventividade e a imaginação se manifestam através de uma linguagem livre, especial, porque envolvente. Uma prática que possibilita o intercâmbio contínuo de experiências entre o contador e o(s) ouvinte(s), todos envolvidos em um mundo fictício onde prevalecem o riso, o encantado, a fantasia, o mistério.

Adaptando esse pensamento, afirma-se que só os que tiveram o privilégio de narrar histórias e observar olho no olho a reação de encantamento do ouvinte, mesmo os adultos que, em geral, se fecham em suas cascas de maturidade, com medo de permitirem a si momentos de prazer com um texto literário, sabem quão saudável é integrar-se e entregar-se a essa atividade. Atividade que além de compor nosso patrimônio oral pode reatar o fio que liga o passado e o presente, e constrói a temporalidade pessoal do cidadão-leitor.

Oralidade ancestral é o ato humano de expressar ideias e sentimentos com voz viva, e a nova oralidade é a transmissão oral mediada por uma tecnologia, sendo ela simples ou sofisticada. Na atualidade, pelo menos na sociedade brasileira, há um misto das duas oralidades. Usa-se com muita intensidade a voz viva e também os recursos de comunicação com a voz mediatizada que é classificada como Nova Oralidade. 


\title{
A Nova Oralidade
}

A transmissão, por voz mediatizada, de programas jornalísticos no rádio, na televisão, na internet continua aproximando cada vez mais o leitor-ouvinte dos textos informativos e literários.

Zumthor, ao abordar a oralidade mediatizada, alerta que esse gênero coexiste com as demais oralidades. Portanto,

\begin{abstract}
é inútil julgar a oralidade de modo negativo, realçando-lhe os traços que contrastam com a escritura. Oralidade não significa analfabetismo, o qual, despojado dos valores próprios da voz e de qualquer função social positiva, é percebido como uma lacuna. Como é possível conceber realmente, intimamente, o que pode ser uma sociedade de pura oralidade (supondo-se que tenha existido algum dia!), toda oralidade nos parece mais ou menos como sobrevivência, reemergência de um antes, de um início, de uma origem. Daí ser freqüente, nos autores que estudam as formas orais da poesia, a idéia subjacente - mas gratuita - de que elas veiculam estereótipos "primitivos". (2010, p. 24-25).
\end{abstract}

Para discutir a nova oralidade, mesmo que de uma forma sucinta, traz-se a seguinte ideia de Ong (1998, p. 11): "A era eletrônica é também uma era de 'oralidade secundária', a oralidade dos telefones, do rádio e da televisão, cuja existência depende da escrita e da impressão."

Observa-se que a literatura ligada à oralidade, pelo menos aquela a qual se teve acesso na construção desse trabalho, em sua maioria, apresenta a expressão nova oralidade escrita em itálico. Talvez isso signifique uma situação "mal resolvida". Provavelmente exista no ar uma dúvida se é honesto assumir as manifestações por meio da voz produzida via tecnologia como uma oralidade natural.

De fato não o é. Acredita-se que é nesse sentido que McLuhan (1972, p. 371) pergunta: "quais serão as novas configurações do mecanismo e da cultura letrada ao serem essas formas mais velhas de percepção e julgamento invadidas pela nova idade da eletricidade?"

A presença cada vez maior de tecnologias no cotidiano brasileiro demonstra a importância que ela tem em todos os âmbitos: pessoal, profissional, comercial...

O que deve ser destacado, porém, é que a Nova Oralidade, apesar da palavra Nova, não é uma criação atual e a História comprova isso com uma extensa lista de invenções. 
Num rápido retrospecto histórico, lembra-se que o primeiro aparelho que tornou possível a escuta da voz à distância foi o telefone fixo, em 1876. Ele não apenas facilitou a comunicação como aproximou famílias e amigos distantes, por meio da voz. Muitos anos depois o telefone móvel ou celular trouxe maior rapidez, facilidade e comodidade, tornando cada vez mais difícil acompanhar tanta novidade.

$\mathrm{Na}$ área de telefonia outra invenção, mas com preço ainda inacessível para a maioria da população, é o videofone, que além da voz, traz também imagens em tempo real.

A penetração da música em localidades afastadas dos centros culturais privilegiados ocorreu graças ao disco de vinil, em 1887. Nos dias atuais pode-se ouvir música de maneira portátil graças à criação de incontáveis produtos, entre eles: CDs, MPs, iPOD etc.

O rádio, desde que foi testado com transmissão transatlântica em 1901, passa a ser uma presença diária em diferentes países e ambientes, também reduzindo a demora por informação, divertimento, cultura e novidade.

Depois do rádio veio a televisão, que integra som e imagem, traz notícias e lazer de maneira instantânea para os telespectadores. Atualmente ela é adquirida com maior facilidade até por pessoas com poucos recursos financeiros.

Acredita-se que com esse trajeto foi possível perceber a propagação da voz em suportes diversificados, mas reitera-se o pensamento de Almeida (1994, p. 26) quando destaca que "o cinema e a televisão têm sua origem na fala, na oralidade, na corporalidade da voz e do corpo, da natureza, da imagem do mundo."

No cinema, a escuridão da sala influi duplamente sobre os espectadores-ouvintes de um filme. Ela os submete aparentemente à sua solidão; entretanto, eles sabem confusamente juntos - 0 bastante para que, por vezes, se esboce uma reação comum. [...] Pela abertura da tela, voyeur de objetos e de ações em 'tamanho natural', meu olho somente percebe um corte no real, emoldurado pela sombra. Mas o quadro não encerra o que capta o ouvido. Parece que foi reconstituída a situação de performance direta. (ZUMTHOR, 2010, p. 269-270).

Com o advento da internet há uma relação presença-ausente em que as pessoas se comunicam escrevendo ou falando por intermédio do email, chat, orkut, MSN, facebook, twitter, entre outras iniciativas que acabaram criando as chamadas netiquetas (etiquetas na internet). Etiquetas que regem não apenas 0 
comportamento dos internautas, mas também a linguagem utilizada por eles nesse espaço.

Santos (2005, p. 157) ao pesquisar as "interações on line (IOL)" de adolescentes de 13 e 14 anos, observa que apesar de sabermos, no senso comum, que "falar é diferente de escrever", na rede de computadores, o adolescente:

[...] ao escrever o que pensa, lança mão de recursos lingüísticos que fogem dos aspectos formais da escrita e busca "imitar" a informalidade e espontaneidade do discurso oral cotidiano, através do uso de onomatopéias, alongamentos de vogais e consoantes, entre outros elementos.

Essa transposição acredita-se ser resultado da forte presença da oralidade em nossas vidas. Em consequência disso novos recursos de comunicação mediatizados vão sendo inventados incessantemente e talvez pela necessidade de realmente ouvir o outro, desenvolveu-se o skipe que reunindo voz e imagem cria a sensação de proximidade e muitas vezes também a eliminação da saudade.

\begin{abstract}
A socialidade que, no cotidiano da existência, alimenta a voz viva, transmuta-se em hipersocialidade circulando nas redes de telecomunicação, constitutivas de um novo vínculo coletivo: socialidade de síntese, agindo sobre elementos separados e fragmentados dos grupos estruturados tradicionais. (ZUMTHOR, 2010, p. 27).
\end{abstract}

Quando Zumthor refere-se a voz mediatizada, possivelmente ele está apontando para o processo artificial de textos oralmente registrados em diferentes veículos de comunicação. Usa-se a palavra artificial ao concordar com Almeida (1994, p. 45) quando ele afirma que as "imagens e sons que são simulações do real [...] se tornam reais devido a suas identificações com a oralidade da fala [...]"

Além disso, como defende Rocha (2003, p. 59) o

[...] círculo dos narradores e seus ouvintes, assim como no teatro, a voz e o corpo constituíam uma materialidade praticamente oposta à que foi criada com o advento e a difusão da imprensa, pois pelo contrário, os tipos impressos tenderam a excluir o corpo do circuito comunicativo. Já os meios audiovisuais promoveram um retorno inesperado do corpo, embora sob o signo da virtualidade $e$ geralmente apresentado em imagens fragmentadas. 
Jerusa Pires Ferreira, tradutora dos livros de Paul Zumthor, comenta que: "as oralidades que antes tinham no corpo a própria mídia passam de voz viva aos meios acústicos, eletrônicos, ou em rede. $E$ isto tem a ver com a modernização e é inevitável." (FERREIRA, 2008). Inevitável e útil, pois muitas famílias estão se beneficiando com o skipe, por exemplo. Em especial, as que têm familiares morando em países longínquos se comunicam com voz e imagem nítidas. A imprensa jornalística tem registrado exemplos de funerais compartilhados via internet, em virtude da impossibilidade temporal ou financeira para o deslocamento de amigos e familiares até o local em que o corpo está sendo velado.

Nesse sentido não se pode duvidar de que estejamos [...] no limiar de uma nova era da oralidade, sem dúvida muito diferente do que foi a oralidade tradicional; no seio de uma cultura na qual a voz, em sua qualidade de emanação do corpo, é um motor essencial da energia coletiva. (ZUMTHOR, 2007, p. 82-83).

Abordando a nova oralidade é necessário destacar que: "a diferença é que a voz do computador não é a nossa, portanto, o tom, a modulação, a ênfase e outros instrumentos para entender 0 texto foram estabelecidos fora de nossa compreensão." (MANGUEL, 2000, p. 277). Talvez as vozes mediatizadas por meio das tecnologias sejam uma tentativa de aproximar o leitor-ouvinte de uma voz real, mas a presença que elas proporcionam é diferente, pois é uma presença-ausente.

McLuhan já alertava que mudanças sempre trouxeram polêmicas, por exemplo, "em volta deste tema, se consome diariamente muita emoção e controvérsia na proporção em que nosso mundo se desloca de uma orientação visual para uma orientação auditiva em sua tecnologia elétrica." (1972, p. 51).

Deixando as controvérsias de lado, nota-se que ampliar o uso dos sentidos do humano o torna mais ligado as coisas que ocorrem ao seu redor (mesmo que o redor esteja bem longe do seu quintal). Evidente que isso não garante a sua integração, porém amplia as possibilidades de se integrar ao que McLuhan denominou de aldeia global.

Apesar de a voz presencial ser mais verdadeira, acredita-se que os avanços das tecnologias buscarão sempre novos recursos para reproduzir a voz de forma mais natural possível, visto que a estrutura dinâmica da sociedade atual tem levado o indivíduo, desde a mais tenra idade, a utilizar o aparelho auditivo e fonador nas mais diferentes comunicações. 
Francisco Gregório Filho, contador de histórias brasileiro, um dos idealizadores da Casa da Leitura no Rio de Janeiro, escreveu no texto - Oralidade, afeto e cidadania que:

\begin{abstract}
A oralidade, a escrita e as imagens são linguagens que convivem, mantendo suas importâncias específicas. Uma não desmerece a outra: complementa-a. Na vida, mesmo no mundo contemporâneo, cada linguagem tem sua parcela de contribuição para a interação dos homens, qualificando as relações. (1999, p. 61).
\end{abstract}

Refletindo a respeito das bibliotecas é possível afirmar que a leitura realizada por meio de tecnologias nesse espaço ainda não é satisfatória, pois estas ainda possuem acervos essencialmente compostos de material escrito, reforçando a função da biblioteca como uma instituição social que privilegia o cidadão que domina as letras impressas, deixando uma numerosa população afastada dessa fonte de conhecimento.

Essa é uma responsabilidade do bibliotecário, que deve estar mais disposto a ter iniciativas que permitam ao leitor manifestar-se pela fala ou receber informações e literatura por meio da oralidade.

\title{
A Ética na Mediação Oral da Literatura
}

A Humanidade tem um universo vocal surpreendente $e$ isso pode ser observado em várias situações cotidianas como os eventos acadêmicos que, nos intervalos, produzem uma massa incontrolável de burburinho, numa expressão autêntica e espontânea do ser humano. No entanto, dois fatores têm dificultado o diálogo, em especial, nas metrópoles: o ruído excessivo que tem levado o cidadão a ouvir muito barulho e pouca voz humana e, o acúmulo de fazeres cotidianos, a pressa e a luta pela sobrevivência que impedem as pessoas de pararem para ouvir umas as outras.

[...] uma das características fundamentais da oralidade está ligada a seu caráter de exterioridade e de vivência coletiva. "Palavras ditas ao vento" são inúteis, ensina a sabedoria popular, já que a voz que ressoa precisa ser ouvida para cumprir seu destino. Assim sendo, uma cultura marcada pela oralidade é também uma cultura que preza a experiência coletiva, enquanto que a escrita tende a criar uma situação de maior isolamento entre os indivíduos. (MEDEIROS, 2007, p. 72). 
Uma maneira de ampliar as vozes em defesa das narrativas orais é a prática constante da mediação oral da literatura que, na concepção de Bortolin (2010, p. 137), "é toda intervenção espontânea ou planejada de um mediador de leitura visando a aproximar o leitor-ouvinte de textos literários seja por meio da voz viva ou da voz mediatizada."

Observando, nos últimos anos, mediações em diferentes espaços, provoca nos interessados por essa questão a fazerem o seguinte questionamento: será que os mediadores de leitura estão sendo éticos em suas ações? Vale destacar que aqui a palavra ética é usada no sentido amplo: parte da filosofia que estuda os deveres do homem.

Pensando dessa forma, deve-se refletir a respeito do comportamento ético do mediador oral no seu cotidiano. Antes, porém, buscou-se a origem da palavra ética. Ela vem do grego ethiké e do latim ethica sendo que ambas referem-se à Moral. No entanto, Martins argumenta que entre ética e moral há uma diferença "[...] a primeira reflete sobre os fundamentos e princípios da vida moral, a moral estabelece as regras do que é considerado boa conduta, dentro de um tempo histórico e de uma cultura determinada." (1994, p. 3).

A ética como uma filosofia moral também estabelece código para o exercício de uma profissão por meio do ato ético, que segundo Martins (1994, p. 4) "[...] tem a mesma estrutura de qualquer ação moral, ou seja, tem o aspecto normativo (que se refere a regras da ação) e o fatual (a realização efetiva do ato)."

Poucos estudiosos se preocupam com a ética na leitura, um deles é Manguel (2000, p. 14) quando afirma: "creio que há uma ética da leitura, uma responsabilidade no modo como lemos, um compromisso que é tanto político como privado no ato de virar as páginas e seguir as linhas."

Avalia-se que essa ideia, além de enriquecer essa discussão, reforça a responsabilidade de todos os leitores, visto que, exige-se ética de quem produz um texto, mas também de quem o lê.

Tratando da metodologia de interpretação literária, Miller (1995, p. 77) defende:

[...] essas pessoas que participam de comitês e conselhos editoriais têm uma enorme obrigação moral. É a obrigação de decidir, em última análise, o que vai ser publicado, quem vai lecionar e o que vai ser ensinado. [...] questões sobre o valor e a utilização da literatura, 
questões sobre as responsabilidades éticas e políticas de escritores, professores, e daqueles que escolhem os professores [...]".

Transferindo essa ideia para a área da Biblioteconomia, o mesmo pode ser dito dos bibliotecários que têm a responsabilidade desde a seleção e aquisição dos materiais até a mediação dos textos contidos neles.

Sem a intenção de aprofundamento, pode-se também trazer e adaptar para a Biblioteconomia os três aspectos do que Miller denomina de "nova ética da leitura de Miller: 1) "a obrigação ética primária do professor de literatura [bibliotecário mediador de literatura] é para com a obra literária" (contar como ela é na realidade); 2) "sua obrigação primária será e deve ser filológica" (amor pela linguagem) e 3) atenção para a "tradução" (não confiar numa tradução, se possível, "devemos nós mesmos ler o livro, no original”). (1995, p. 85-88).

No entanto, o presente trabalho preocupação primordial é com a realização efetiva e ética do ato da mediação oral da literatura e o comportamento ético-moral do bibliotecário-mediador. Comportamento que norteará, entre outras ações, as elencadas a seguir:

- proporcionar ao leitor o contato com textos integrais, não compactuando com iniciativas em que são utilizados apenas resumos e resenhas que empobrecem a obra literária;

- realizar rodas de leitura, selecionando textos de qualidade literária, vibrando e fazendo vibrar aqueles que terão contato com esse texto, com entusiasmo e encantamento;

- diversificar os gêneros textuais, as temáticas, os autores, as escolas literárias, para que o leitor tenha uma percepção plural das sociedades, das culturas e da vida;

- planejar cuidadosamente os espaços de leitura, respeitando as necessidades e a liberdade do leitor, o seu conforto físico, sua aprazibilidade;

- diversificar o acervo, não restringindo o acesso aos textos literários apenas em suporte impresso, desprestigiando os leitores nativos digitais;

- arranjar o acervo de maneira acessível, sem "esconder" determinados livros com temáticas proibidas, de valor aquisitivo alto ou controlando 0 empréstimo rigidamente por faixas etárias; 
- adquirir equipamentos que utilizem recursos sonoro e oral, sem a preocupação de considerá-los ruidosos, dispersivos e concorrentes do livro;

- dar visibilidade ao mediador para que ele seja um modelo a ser seguido, quebrando a rotina dos adultos que mandam ler, mas não leem;

- dialogar com o leitor sobre o texto lido, escutado-o, oportunizando uma coautoria mais explícita e partilhada.

Além disso, é fundamental proporcionar à leitura no ambiente web, pois nele cada vez mais, o leitor poderá encontrar páginas contendo textos literários veiculados por meio de vozes midiatizadas.

a responsabilidade ética [...] deve prevalecer na relação bibliotecário versus (vs.) usuário, no sentido de transformar ou realizar a passagem da "velha" realidade do papel para a nova realidade de documentos digitais no ciberespaço. (TARGINO, 2011, p. 132).

Então ser ético é nortear suas práticas tendo como base as necessidades do seu leitor-ouvinte. O mediador oral deve ter, além de conhecimento, sensibilidade para não colocar em primeiro lugar as suas próprias vontades. Precisa superar as dificuldades e entraves que atrapalham as mediações da literatura, visto que na sociedade atual "o imaginário tende a ser mal visto num universo obcecado pela objetividade, opressora do sonho e da fantasia [...]". (OLIVEIRA, 2002, p. 39).

Assim, a tarefa de mediar literatura é desafiadora, principalmente num país em que o índice de leitura ainda não é satisfatório, portanto, o mediador de leitura torna-se fundamental para a formação dos leitores.

\section{CONSIDERAÇÕES FINAIS}

Com essas argumentações foi possível demonstrar que tanto a oralidade ancestral quanto a nova oralidade (mediatizada) estão presentes abundantemente em nossas vidas.

Por outro lado é possível perceber o uso de múltiplos espaços com diferentes profissionais descobrindo (ou redescobrindo) e propondo narrativas orais, isto possivelmente deve-se ao fato de que se ampliou a percepção da oralidade como forma de aglutinamento social e cultural. 
$\mathrm{Na}$ rede de computadores a todo instante são incluídas vozes com narrativas que despertam a atenção e curiosidade, os conteúdos dessas postagens são diversificados. Só para citar exemplos ligados à literatura, há entrevistas, depoimentos, roda de conversas com diferentes profissionais, cobertura de eventos, transliteração de obras literárias em linguagem fílmica, história em quadrinhos com animação, curta metragens; muitas dessas experiências são desenvolvidas de forma "caseira", oportunizando ao cidadão comum (às vezes apenas com o recurso de celular) tornar-se um disseminador de oralidade ou um praticante da voz.

Ao rememorar cenas coletivas em que o indivíduo usa seu suporte vocal a lista é extensa, mas vale lembrar: intervalos de aulas escolares, porta de cinema, teatro e casa de shows, bares, arquibancadas, casamentos e até velórios, quando há a reunião de muitas pessoas. Isso acontece porque as manifestações coletivas formam uma cadeia de voz, uma rede tecida espontaneamente.

Apesar da disponibilidade de tempo na atualidade estar diminuindo em virtude da carga de compromissos (familiares, escolares e profissionais) é uma iniciativa saudável reservar momentos de oralidade, em que cada um possa contar histórias acontecidas durante a semana. Narrar suas leituras de mundo e para que isso ocorra não é necessário um espaço formal/reservado, apenas a abertura de um espaço de tempo em nossas vidas.

Numa atitude saudosista é fundamental resgatar, mesmo de forma ínfima, o tempo para ouvir contos da carochinha e histórias do arco da velha, com maior tranquilidade; num mínimo retorno à oralidade ancestral.

Agradecemos a Fundação Araucária/Secretaria da Ciência, Tecnologia e Ensino Superior do Paraná pela Bolsa de Doutorado.

\section{REFERÊNCIAS}

ABRAMOVICH, Fanny. Literatura infantil: gostosuras e bobices. São Paulo: Scipione. 2001.

ALMEIDA, Milton José. Imagens e sons. São Paulo: Cortez, 1994. (Coleção Questões da Nossa Época, v. 32).

AYER, Maurício. Um ator não é apenas um repetidor de falas. Disponível em: <http://www.wooz.org.br/teatroator.htm>. Acesso em: 10 jan. 2009. 
BORTOLIN, Sueli. Mediação Oral da Literatura: A voz dos bibliotecários lendo ou narrando. 2010. 232 f. Tese (Doutorado) - Faculdade de Filosofia e Ciências, Universidade Estadual Paulista, Marília, 2010.

ESTÉS, Clarissa Pinkola. O dom da história: uma fábula sobre o que é suficiente. Rio de Janeiro: Rocco, 1998.

FERNANDES, Frederico Augusto Garcia. Entre histórias e tererés: o ouvir da literatura pantaneira. São Paulo: Ed. UNESP, 2002.

FERREIRA, Jerusa Pires. Oralidade, mídia, cultura populares. Disponível em: $<$ http://www. intermidias.com/anterior/categorias/lite_jerusa_oralidade.htm>. Acesso em: 2 ago. 2008.

FLECK, Felícia de Oliveira. A profissionalização do contador de histórias contemporâneo. 2009. Dissertação (Mestrado em Ciência da Informação) Universidade Federal de Santa Catarina, Florianópolis.

GAGNEBIN, Jeanne Marie. Prefácio: Walter Benjamin ou a história aberta. In: BENJAMIN, Walter. Magia e técnica, arte e política: ensaios sobre literatura e história da cultura. São Paulo: Brasiliense, 1994. (Obras Escolhidas, v.1).

GOMES, Adriano Lopes. O tempo tece o verbo na voz: o contador de histórias e as memórias de leitura. Revista Vivência, Natal, n. 29, p. 23-32, 2005.

GREGÓRIO FILHO, Francisco. Oralidade, afeto e cidadania. In: BARZOTTO, Valdir (Org.). Estado de leitura. Campinas: Mercado de Letras, 1999. p. 60-63. (Coleção Leituras no Brasil).

MANGUEL, Alberto. A cidade das palavras: as histórias que contamos para saber quem somos. São Paulo: Companhia das Letras, 2008.

No bosque do espelho. São Paulo: Companhia das Letras, 2000.

MARTINS, Maria Helena Pires. A ética em questão. Palavra-chave, São Paulo, n. 8, out. 1994.

MCLUHAN, Marshall. A Galáxia de Gutenberg. São Paulo: Companhia Editora Nacional, 1972.

MEDEIROS, Vera Lúcia Cardoso. Quando a voz ressoa na letra: conceitos de oralidade e formação do professor de literatura. Organon, Porto Alegre, n. 42, p. 6984, jan./jun. 2007.

MILLER, J. Hillis. A Ética da leitura: ensaios 1979-1989. Rio de Janeiro: Imago, 1995. (Biblioteca Pierre Menard).

MONIZ, Antônio; PAZ, Olegário. Dicionário breve de termos literários. Lisboa: Editorial Presença, 1997. 
MONTENEGRO, Antonio Torres. História oral e memória: a cultura popular revisitada. 3. ed. São Paulo: Contexto, 2001. (Caminhos da História).

NÓBREGA, Nanci Gonçalves da. No espelho, o Trisckster. In: SANTOS, Fabiano dos; MARQUES NETO, José Castilho; RÖSING, Tânia Mariza Kuchenbecker. Mediação de leitura: discussões e alternativas para a formação de leitores. São Paulo: Global, 2009. p. 95-112.

OLIVEIRA, Priscila de Souza. A criação literária e a resiliência. Letras de Hoje, Porto Alegre, v. 37, n. 2, p. 37-46, jun. 2002.

ONG, Walter. Oralidade e cultura escrita. Campinas: Papirus, 1998.

PAVIS, Patrice. Dicionário de teatro. São Paulo: Perspectiva, 1999.

PIACENTINI, Maria Tereza de Queiroz. Não tropece na língua. Disponível em: $<$ http://www.resenhas.com/resenhas/ver.asp?id=1679\&auth=39449\&>. Acesso em: 29 nov. 2009.

ROCHA, João Cezar de Castro. Literatura ou narrativa?: representações (materiais) da narrativa. In: OLINTO, Heidrun Krieger; SCHOLLHAMMER, Karl Erik (Orgs.). Literatura e cultura. Rio de Janeiro: Ed. PUC-Rio; São Paulo: Loyola, 2003. (Coleção teologia e ciências humanas, 14).

SANTOS, Else Martins dos. Chat: e agora? Novas regras - nova escrita. In: COSCARELLI, Carla Viana; RIBEIRO, Ana Elisa (Org.). Letramento digital: aspectos sociais e possibilidades pedagógicas. Belo Horizonte: CEALE; Autêntica, 2005. p. 151-183. (Coleção Linguagem e Educação).

SOUSA, Mari Guimarães. Literatura oral e o imaginário em perspectiva de expansão através do turismo cultural. Disponível em:

<http://www.uesc.br/icer/artigos/mariliteraturaoral.html>. Acesso em: 30 dez. 2008.

TARGINO, Maria das Graças. Aspectos éticos da prática do bibliotecário relacionados às atividades de atendimento aos usuários. In: OLIVEIRA, Maria Odaisa Espinheiro de; FERREIRA, Glória Isabel Sattamini; LUNARDELLI, Rosane Suely Álvares. Ética profissional na prática do bibliotecário. Brasília: Usina de Letras, 2011. p. 132-159.

TOMATES verdes fritos. Direção: Jon Avnet. [S.I.]: Distribuidora: Universal Pictures, 1991. 1 DVD (136 min.), color. Título original: Fried Green Tomatoes.

ZUMTHOR, Paul. Escritura e nomadismo. Cotia: Ateliê Editorial, 2005.

. Introdução à poesia oral. Belo Horizonte: UFMG, 2010.

Performance, recepção, leitura. São Paulo: EDUC, 2007. 


\title{
Title
}

Orality and Literature on Mediation Ethics

\begin{abstract}
Introduction: This paper discusses the two oral expressions, the ancient and the New Orality. The first is the one produced in person, through live voice and that is present in daily life in society. The second, also present in daily life, is different of the first to be done by medias, this is, publicised relocation, i.e., constructed and disseminated by a technology. It is a theoretical work that is backed by authors of the Information Science, Arts and Letters.

Objective: Cause reflections on information professionals on the importance of the use of these oral expressions in daily life of different spaces, be it informational, cultural, educational, business, or research

Methodology: Bibliographical method chosen for this research.

Conclusions: It is concluded that there is a movement, although shy, in multiple spaces offering oral narratives for diverse age range. There's also the inclusion and dissemination of voices in computer networks, enabling a social and cultural aglutinamento.
\end{abstract}

Key words: Orality. Mediation of literature. Professional ethics

\section{Título}

Oralidad y Literatura sobre Mediación Ética

\section{Resumen}

Introducción: Este artículo discute las dos expresiones orales, la antigua y la nueva oralidad. El primero es el producido en persona, a través de la voz viva y que está presente en la vida cotidiana en la sociedad. El segundo, también presente en la vida cotidiana, es el primero en ser publicitado de reubicación, que es construido y difundida por una tecnología. Es un trabajo teórico que es apoyado por autores del área de Ciencias de la información, artes y letras.

Objetivo: Provocar reflexiones de profesionales de la información sobre la importancia del uso de estas expresiones orales en la vida diaria de los diferentes espacios, ya sea informativo, cultural, educativo, empresarial, o investigación.

Metodología: Método bibliográfico elegido para esta investigación.

Conclusiones: Se concluye que existe un movimiento, aunque tímido, en múltiples espacios ofreciendo narraciones orales para diversas edades. También es la inclusión y difusión de voces en redes de computadoras, lo que permite una aglutinamento social y cultural.

Palabras clave: Oralidade. mediación de la literatura. ética professional.

Recebido em: 15.07 .2014

Aceito em: 05.10.2014 